\title{
Twitching Motility, Biofilm Communities in Cephalosporin Resistant Proteus spp and the Best in vitro Amoxicillin Susceptibility to Isolates
}

\author{
Aktar Uzzaman Chouduri*, Abdul Wadud \\ Department of Pharmacy, University of Rajshahi, Rajshahi, Bangladesh \\ *Corresponding author: auchow5@yahoo.com; auchow5.pharm@ru.ac.bd \\ Received December 16, 2013; Revised December 23, 2013; Accepted January 10, 2014
}

\begin{abstract}
Proteus strains isolated from tap water are assessed for their twitching motility and biofilm formation on urethral catheter strips of two selected brands, Protos and Huaian, since these strains are the common cause of catheter associated urinary tract infection (CAUTI). Neither the strains of high swarming motility nor of high antimicrobial resistance enabled to twitch over the catheter strips. All of high antibiotic resistant strains were found to form biofilm on PVC strip, few strains on Huaian catheter strip and one strain (Pv) on both catheter strips. Based on biofilm quantification study, the urethral catheter from Protos brand was relatively safer than that of Huaian brand to prevent CAUTI. Moreover, Proteus isolates were strong resistant to cotrimoxazole (folate synthesis inhibitor) and cephalosporins (cell wall synthesis inhibitor). Underlying the $\beta$-lactam group, strong cephalosporin resistance and amoxicillin susceptibility in isolates indicated that the isolates were non $\beta$-lactamase producer. Tested antibiotics underlying the protein and DNA synthesis inhibitors were satisfactorily effective for the inhibition of Proteus isolates. The phenolic acid, $-\mathrm{C}_{6} \mathrm{H}_{4} \mathrm{OH}$, present in the chemical formula of amoxicillin plays a crucial role in cell wall synthesis of Proteus isolates allowing more drugs to cell wall via porins.
\end{abstract}

Keywords: Proteus, urethral catheter, biofilm, cephalosporin resistance, amoxicillin sensitivity

Cite This Article: Aktar Uzzaman Chouduri, and Abdul Wadud, "Twitching Motility, Biofilm Communities in Cephalosporin Resistant Proteus spp and the Best in vitro Amoxicillin Susceptibility to Isolates.” American Journal of Microbiological Research 2, no. 1 (2014): 8-15. doi: 10.12691/ajmr-2-1-2.

\section{Introduction}

Aerobic Proteus bacteria are the third most common cause of UTI after E. coli and S. saphrophyticus. It causes urine stone due to presence of urease and also causes wound infection, septicemia, and pneumonia mostly in hospitalized patients. About 50\% patients requiring an indwelling urethral catheter for 5 days or longer will develop bacteriuria or candiduria [1,2,3]. Silent CAUTI comprises a huge reservoir of antibiotic-resistant organisms in the hospital [4,5]. Adverse consequences of CAUTI include local and systemic morbidity, secondary bloodstream infection, death, a reservoir of drug-resistant microorganisms, and increased health care costs $[6,7,8]$.

Three types of movement identified in the genus Proteus are swimming, swarming and twitching. Proteus bacteria use swimming motility in liquid media. Six to ten flagella are present on the bacterial surface required for their swimming motility. Swarming motility requires an increased number of flagella and this type of motility is used for movement on solid surfaces. Swarming motility is the typical mode of movement of Proteus grown on solid agar, the Rauss phenomenon. With twitching motility, the bacteria twitch between two solid surfaces $[9,10]$.
An important virulence factor in Proteus is biofilm formation: an attached structure with microbial cells and populations embedded in a polysaccharide layer. The biofilm enables better adaptation of bacterial cells to the conditions of the external environment and facilitates survival at adverse external environment [11]. Biofilm are the most common mode of bacterial growth in nature and are also important in clinical infections, especially due to the high antibiotic resistance associated with them $[12,13,14]$. Antibiotic resistance is found more often in strong biofilm formers than in weak biofilm formers. Hola et al. 2012 showed that this trend in Proteus bacteria isolated from urinary catheter is generally strongest for cotrimoxazole and ciprofloxacin resistance [15]. Another study have shown that strains of Escherichia coli O157:H7, grown in a single strain culture, do not form robust biofilm on solid surfaces, but rather form small clusters of attached cells $[16,17,18]$ or completely fail to attach [19].

A biofilm is an aggregate of microorganisms immersed in a polysaccharide matrix adherent to each other and to the airway mucosa. Biofilm-forming bacteria are protected from phagocytosis, antimicrobial agents, and the ciliary action of the airway epithelial cells. Furthermore, microorganisms gathered in a biofilm significantly develop different genetic properties compared to planktonic species. Donlan 2001 isolated Proteus 
mirabilis from indwelling medical device urinary catheter, one of the biofilm-associated microorganisms among others [20]. From municipal supplied water we isolated and identified eleven Proteus strains belonging four species [21] and we have shown that the microbial contaminants came from fecal origin, and only amoxicillin was fully effective for the inhibition of isolates [22,23]. The isolates' catheter-associated pathogenic features remain to be elucidated. Therefore, the purpose of the present study was to assess (1) the biofilm forming abilities of Proteus isolates in relation to their drug resistances, (2) the kinetic study of catheter-associated swarming and twitching motilities, and (3) the cause of amoxicillin potentiality in multi-drug resistant Proteus inhibition.

\section{Materials and methods}

\subsection{Bacterial Strain, Culture Medium, Medical Device}

Eleven Proteus strains belonging four species, Proteus mirabilis (Pm), P. vulgaris (Pv), $P$. hauseri $(P h)$ and $P$. penneri $(P p)$, isolated and identified from 100 samples of municipal tap water in our previous study [21] have been used in this study. All chemicals were purchased from Sigma-Aldrich, Difco, Thermo Scientific, Oxoid unless it is mentioned otherwise. Brain-Heart infusion (BHI) medium was purchased from Hi-media, India and MacConkey agar medium from Accumedia, Spectrum Chemicals and Laboratory Products, USA. Two catheter bags - (1) Urine Drainage Bag 2000 ml, Protos Medical Products Co. Ltd, Houston, Texus, USA, (2) National Urine Drainage Bag 2000 ml, Huaian Angel Medical Instruments Co. Ltd, Chaina- were purchased from local market.

\subsection{Morphological Analysis and Biochemical Test}

The morphology of isolates was examined under microscope (Rinocular photographic microscope, M2100, Germany) by Gram staining method with $40 \times$ and $800 \times$ objectives. The cells were Gram-negative, rod in shape, singly arranged non-diploid or clump predicting the family Enterobacteriaceae. By sequential biochemical analyses the bacterial isolates were identified as Proteus species [21]. Five basic sugars- glucose, lactose, mannitol, maltose and sucrose were used in carbohydrate fermentation test for the genus and species identification.

\subsection{Preparation of Catheter Strip}

Based on the market price two catheter bags from two different companies, Protos, USA (Highest price) and Huaian, China (lowest price), were purchased from local market and were aseptically cut into strips $\left(1 \times 8 \mathrm{~cm}^{2}\right)$. The strip was submerged with $10 \mathrm{ml}$ of BHI medium in a test tube and used for biofilm formation and quantification assay.

\subsection{Test for Twitching Motility over Catheter Strip}

The catheter strips $\left(1 \times 8 \mathrm{~cm}^{2}\right)$ were cut aseptically and placed on the LB agar plate across the diameter line. After placement the strip was gently pressed to make the contiguity of horizontal plane and uniform adherence of the strip onto the surface of agar medium.

\subsection{Assay of Biofilm Formation}

Biofilm formation was assayed qualitatively based on the ability of bacterial cells to adhere on the surface of polyvinylchloride plastic (PVC), a material used to make catheter lines (Urine drainage bag and tubing) [24]. The catheter tube filled with BHI medium was inoculated with Proteus isolates followed by the overnight incubation at room temperature with mild shaking. The medium was discarded and the tube was repeatedly rinsed with water, PBS pH 7.2 and water. After drying under laminar air flow the adherent cells on the inner surface of the tube was stained with $1 \%$ crystal violate $(\mathrm{CV})$ solution that stained the cells but not the PVC. The tubes were visualized to check the intensity of violet color and the rough scores were noted compared to that of control.

\subsection{Quantification of Biofilm}

The assay of quantitative biofilm formation was adapted from the method described elsewhere [25,26] which is based on the ability of bacterial cells to adhere on solid surfaces and uses CV to stain the biofilm. Briefly, $100 \mu$ l of a standardized bacterial cell suspension $\left(\sim 10^{9}\right.$ $\mathrm{CFU} / \mathrm{ml}$ ) was inoculated in $10 \mathrm{ml}$ of $\mathrm{BHI}$ medium in test tube containing catheter strip (Figure 1) and this solution was incubated at room temperature for $24 \mathrm{~h}$ with mild agitation (50 rpm) on water bath (Advantec Lab-Thermo Shaker, TS-20, Toyo Kaisha, Ltd). A PVC strip of same size was used as control in parallel of two types of catheter strips. The solution was then discarded and the strips were rinsed repeatedly with water, PBS, pH 7.2 and water. After drying, staining for adherent biofilm was performed using $1 \% \mathrm{CV}$ which was then discarded and the strip with adherent cells were rinsed three times with PBS, $\mathrm{pH} 7.2$ to remove weakly adhered cells before drying for $24 \mathrm{~h}$ at room temperature. A quantitative assessment of the biofilm formation was obtained by extracting $\mathrm{CV}$ from the strip with $3 \mathrm{ml}$ per tube of the bleaching solution: ethanol and glacial acetone (70:30). The intensity of coloration was determined at $595 \mathrm{~nm}$ using UV-spectrophotometer (UVmini-1240, Shimadzu, Japan). All strains were tested in three independent experiments and the mean $\mathrm{OD}_{595 \mathrm{~nm}}$ values were determined from three replicates and interpreted using the following scale: positive ( $>0.24)$, weak $(0.12-0.24)$, negative $(<0.12)$ [27].

\subsection{Data Analysis}

For data processing, the software Microsoft Excel 2007 was used.

\section{Results}

\subsection{Isolation and Identification of Proteus Species}

Total 100 samples of municipal supplied water were subjected to a systematic analysis for the isolation and identification of Proteus species. Briefly, the black centered bacterial colonies formed on sample inoculated 
KIA culture plate at $37^{\circ} \mathrm{C}$ were picked up and analyzed for the presence of the genus Proteus. Eleven Proteus isolates of $P m, P v, P h$ and $P p$ designated as $11(P v)$, 66 $1(P p), \quad 66_{2}(P h), \quad 66_{3}(P p), \quad 66_{4}(P p), \quad 66_{5}(P p), \quad 66_{6}(P p)$, 66 $7(P p), 66_{8}(P p), 91_{1}(P m)$, and $91_{2}(P m)$ were identified. Two representative biochemical tests for the identification of Proteus species are shown in Figure 2 and Figure 3. All isolates turned the red color of McConkey agar medium to colorless (Figure 2-I) and were urease positive in urea hydrolyzing reaction (Figure 3A). Isolate $11(P v)$ and $66_{2}(P p)$ showed indole positive reaction (Figure 2-II). All isolates were lactose, mannitol non-fermenters and glucose, sucrose fermenters. Acid production by the isolates was assessed with the color change from red to yellow in carbohydrate fermentation tests (Figure 3B, C). Isolate $91_{1}$ and $91_{2}$ were maltose non-fermeners and identified as Proteus mirabilis (Pm). Details of isolation and identification are described in our previous report [21].

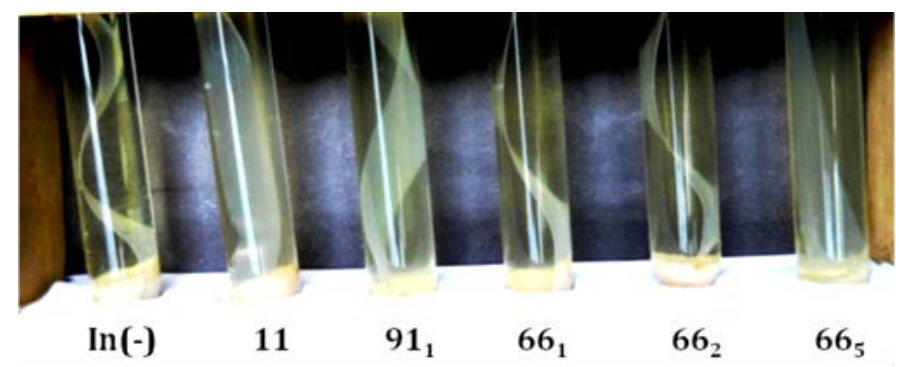

Figure 1. Technique used for biofilm assay. PVC or catheter strips $\left(8 \times 1 \mathrm{~cm}^{2}\right)$ were submerged in tubes containing BHI medium and incubated at $37^{\circ} \mathrm{C}$ with (11, 91 $\left.1,66_{1}, 66_{2}, 66_{5}\right)$ and without (In-) inoculums

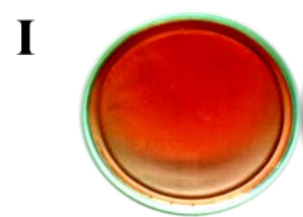

A

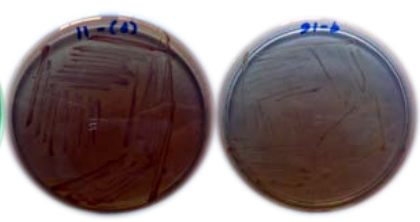

C

II

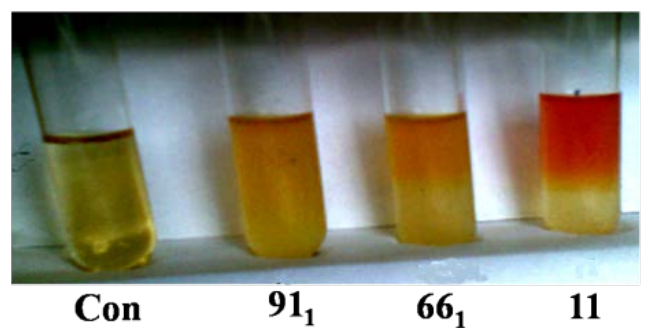

Figure 2. Tests for the identification of Proteus, I: McConkey agar plate. Isolate 11 (B) and $91_{2}$ (C) turns the color of culture plate from orange to colorless. II: Indole test. Indole positive reaction produces a cherry-red ring above the tryptone broth medium. Isolate 11 was indole positive and $66_{1}$, $91_{1}$ were indole negative compared to negative control (con)
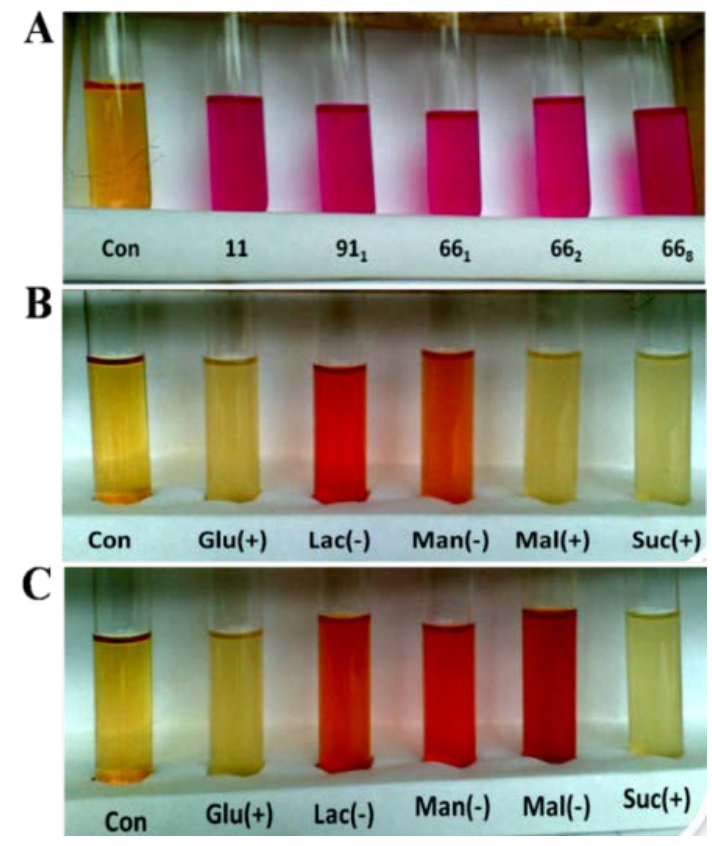

Figure 3. Urease test and carbohydrate fermentation, A: Urea hydrolysis by Proteus isolates turned the color of Christensen's broth medium from reddish to pink. B: Lactose and mannitol non-fermenters were designated as genus Morganella or Proteus. C: Isolate $91_{1}$ was a maltose non-fermenter and identified as Pm. Details are described in our previous study [21] 


\subsection{Kinetics of Swarming Motility}

Each isolate was tested for its swarming growth which is connected with the cell surface components of bacteria and is an important virulence factor in cases of UTIs especially for the genus Proteus. The distinct swarming and consolidation phases were obtained as reported earlier [23]. Here the isolates' competitive swarming motilities up to 44 hours on LB agar medium were kinetically assessed. Four isolates, 91 $1(P m), 91_{2}(P m), 66_{2}(P h)$ and 66 $5(P p)$, showed enhanced swarming motility than others (Figure 4). To date, $P m$ is thought to be a strong swarmer cell among Proteus species and here two isolates, $91_{1}$ and $91_{2}$, of $\mathrm{Pm}$ exhibited faster swarming (Figure 4B,C) than other species resembling with other reports [28]. However, in this study we found an isolate of $P h\left(66_{2}\right)$ which showed strong swarming motility comparable to $\mathrm{Pm}$ (Figure 6 $\mathrm{B}, \mathrm{C}, \mathrm{E})$. The kinetics of swarming motility was studied for these top scorer isolates (Table 1) where we found that the rate of swarming was decreasing with increasing incubation time.

Table 1. Rate of swarming motility

\begin{tabular}{|c|c|c|c|c|c|}
\hline \multirow{2}{*}{$\begin{array}{c}\text { Isolates } \\
\text { (Spp.) }\end{array}$} & \multicolumn{4}{|c|}{ Rate of swarming $(\mathrm{mm} / \mathrm{h})$} & \multirow{6}{*}{$\begin{array}{c}\text { Rate of swarming is } \\
\text { decreased with } \\
\text { increasing time }\end{array}$} \\
\hline & $\begin{array}{c}0- \\
10 ~ h \\
\end{array}$ & $\begin{array}{l}10 \text { - } \\
20 \mathrm{~h} \\
\end{array}$ & $\begin{array}{l}20- \\
25 \text { h } \\
\end{array}$ & $\begin{array}{l}25- \\
44 h \\
\end{array}$ & \\
\hline $91_{1}(\mathrm{Pm})$ & 3.25 & 1.19 & 1.07 & 0.68 & \\
\hline $91_{2}(\mathrm{Pm})$ & 3.82 & 1.35 & 1.20 & 0.68 & \\
\hline $66_{2}(P h)$ & 3.70 & 1.40 & 0.60 & 0.56 & \\
\hline $66_{5}(P p)$ & 2.40 & 1.10 & 0.73 & 0.96 & \\
\hline
\end{tabular}

Four isolates having enhanced swarming motility were analyzed for the rate of swarming.

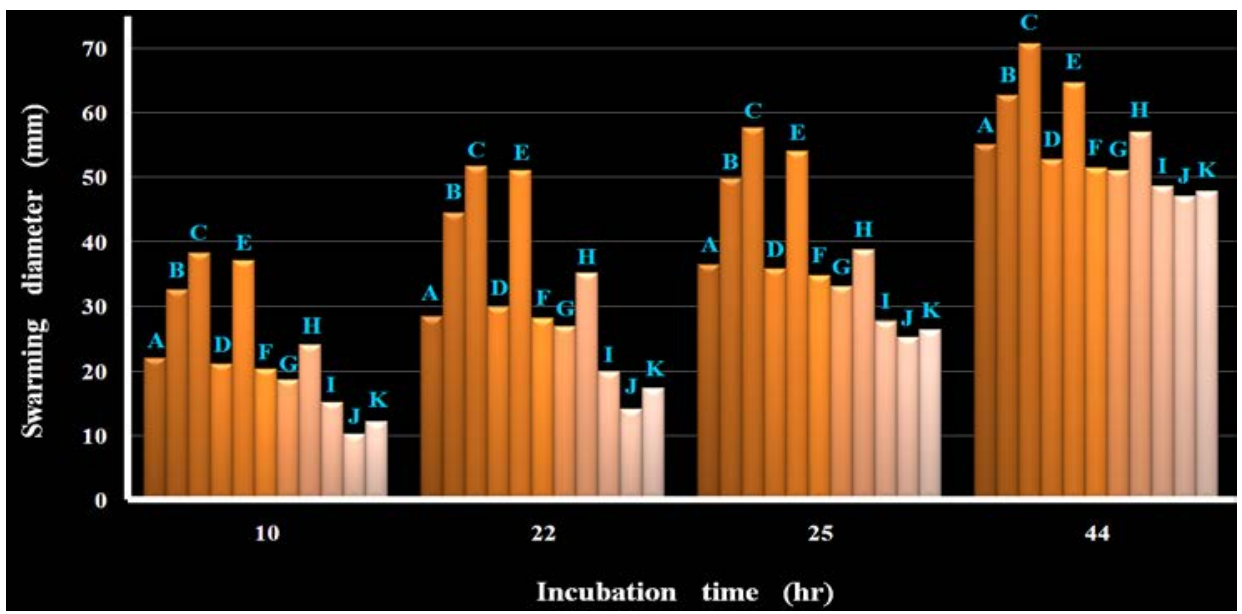

Figure 4. A tiny drop of standardized cell suspension ( $\left.10^{9} \mathrm{CFU} / \mathrm{ml}\right)$ was inoculated at the center of LB agar plates (90 mm diameter) and allowed to grow at $37^{\circ} \mathrm{C}$ over indicated time. Mean swarming diameters obtained from at least three individual directions were plotted. A- 11 ( $\left.P v\right)$, B- $91_{1}(P m)$, C91 2 (Pm), D- 66 1 (Pp), E- 66 2 (Ph), F- 66 3 (Pp), G- 66 4 (Pp), H- 66 $(P p)$, I- 66 6 (Pp), J- 66 7 (Pp), K- 66 8 (Pp). Four isolates, two Pm (B, C), one Ph (E) and one $P p(\mathrm{H})$, showed enhanced swarming motility than that of others

\subsection{Twitching Motility over Catheter Strip}

Next we aimed to investigate whether the isolates of enhanced swarming motility are able to twitch over the catheter bridge since the ascending CAUTIs are very common in patients undergoing catheterization. In practice, $10-50 \%$ of patients undergoing short-term catheterization (up to 1 week) develop infection [29]. Patients undergoing long-term catheterization ( $>1$ month), even with high standards of care, will inevitably develop bacteriuria. Swarming motility has correlated very well with the ability to swarm over the various catheters [15]. Therefore, the four isolates were selected based on their high swarming motility $\left(91_{2}, 66_{5}\right)$ and high antimicrobial resistance $\left(11,91_{1}\right)$ to test for their abilities to twitch over the catheter strip (Figure 5). Freshly prepared strains were inoculated using a pick onto the one half of the plate. After $24 \mathrm{~h}$ incubation at $37^{\circ} \mathrm{C}$, the ability of isolates to twitch over the tested catheter strip was assessed. The strains were divided into two groups as done by other investigators [15,30,31]: (1) Strains not able to bridge the catheter strip and (2) Strains able to bridge the catheter strip. The isolates were found to swarm on the inoculated half of the agar plates but did not cross the catheter bridge (Figure 5). Similar results were obtained for the catheter strips from both Protos and Huaian brand. Hola et al. 2012 found the clinical Proteus isolates which enabled to swarm over the catheter bridge but in this study Proteus isolates from tap water were unable to form a bridge over the catheter strips.

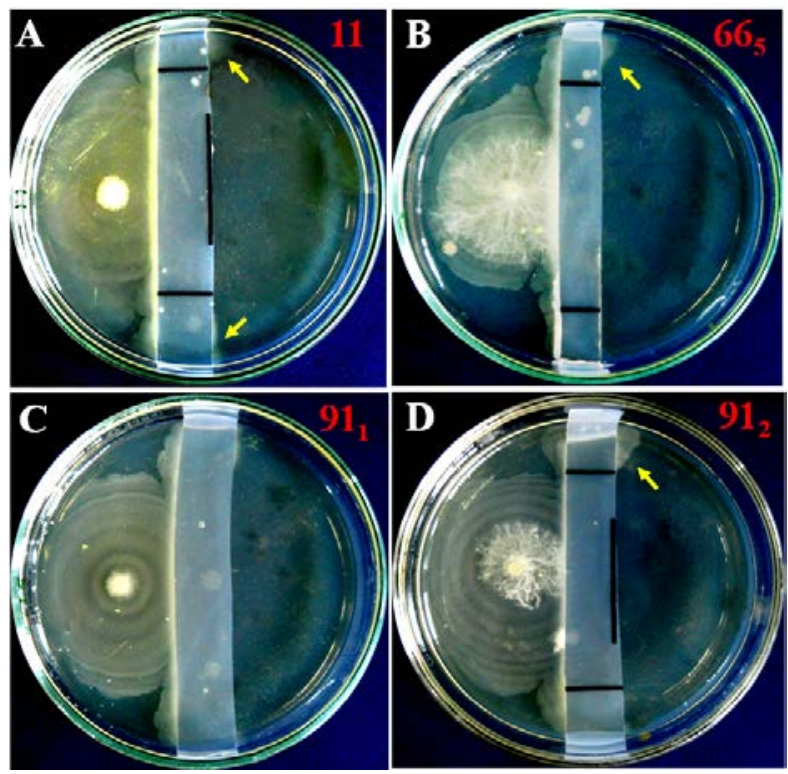

Figure 5. Test for twitching over catheter strip. Four isolates, A: 11(Pv), B: $91_{1}(P m), C: 91_{2}(P m)$, D: $66_{5}(P p)$, of variable swarming motility and antimicrobial resistance were tested for their abilities to twitch over the catheter strip. No isolates crossed over the catheter strips. Arrowheads indicated the swarming growth towards the second half of agar plate through a leakage under the catheter strips 


\subsection{Biofilm Formation and Quantification}

Urine drainage bag from two different brand chosen on the basis of their market price were used for biofilm study. A qualitative biofilm formation assay was carried out using catheter tube with highly resistant isolates of $\mathrm{Pm}$ $\left(91_{1}, 91_{2}\right)$ and $P v(11)$ (Figure 6) since antibiotic resistance was found more often in strong biofilm formers than in weak biofilm formers. The spectrum of resistance in 11 and $91_{1}$ was 0.58 and that in $91_{2}$ was 0.42 [22]. The intensity of $1 \% \mathrm{CV}$ staining revealed that the bacterial cells of these tested strains were attached on the inner surface of the catheter tube compared to that of negative control (Figure 6). The result indicated that the tested strains enabled to form biofilm on the inner surface of catherter tube. We then attempted to quantify the biofilm formed on catheter strip using spectrophotometric method at $\mathrm{OD}_{595 \mathrm{~nm}}$.

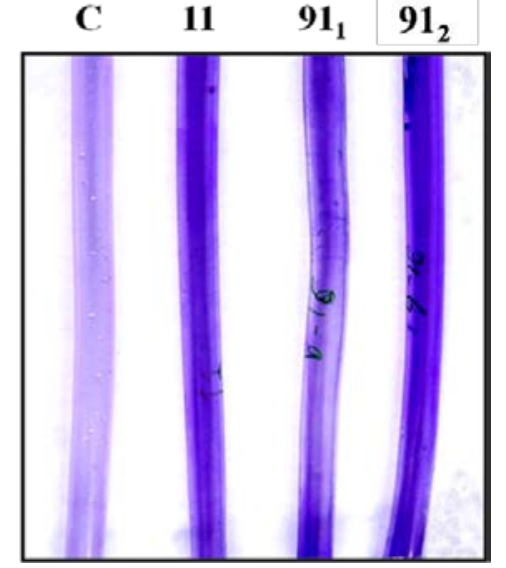

Figure 6. Assay of biofilm formation. Catheter tubes filled with $\mathrm{BHI}$ medium were incubated at $37^{\circ} \mathrm{C}$ with $\left(11,91_{1}, 91_{2}\right)$ and without (C) inoculums. Bacterial cell adherence was assessed by CV staining

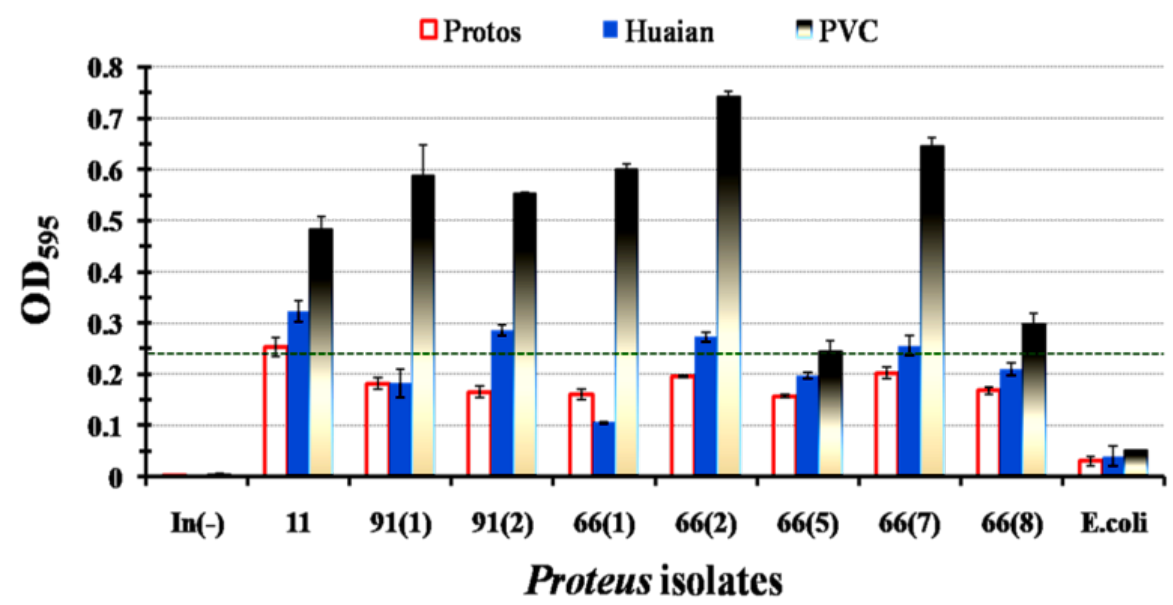

Figure 7. Assay of quantitative biofilm formation. Biofilm formed on PVC strip (gradient filled bar) by isolates $11(P v), 91_{1}(P m), 91_{2}(P m), 66_{1}(P p)$, $66_{2}(P h)$ and $66_{7}(P p)$ were significantly high compared to that on Protos strip (open bar) and Huaian strip (filled bar). In(-): No inoculums; E. coli: Nonpathogenic inoculums. Horizontal dashed line at $\mathrm{OD}_{595 \mathrm{~nm}} 0.24$ indicates the threshold of biofilms formation

The adhesion of bacteria to the catheter depends on many factors, for example surface charge, hydrophobicity or hydrophilicity of the catheter and bacterial cell, and specific genes for adhesion [32]. Therefore, the risk of infection depends on the duration of catheterization and catheter management. Biofilm forming abilities of tested strains on catheter strips from two brands, Protos and Huaian, were compared to that on PVC strip (Figure 7). Based on the spectrophotometric data $\left(\mathrm{OD}_{595 \mathrm{~nm}}\right)$ isolates 11(Pv), 91 1 (Pm), 91 $2(P m), 66_{1}(P p), 66_{2}(P h)$ and 66 $7(P p)$ were found to form biofilm on PVC strip and isolates 91 $2(P m), 66_{2}(P h)$ and $66_{7}(P p)$ positively formed biofilm on Huaian strip since the $\mathrm{OD}_{595 \mathrm{~nm}}$ values were greater than 0.24 (Figure 7). Only isolate $11(P v)$ crossed the threshold 0.24 for both Protos and Huaian strips. However, the urine drainage bag from Protos brand was relatively safer than that of Huaian brand.

\subsection{Cephalosporin Resistance Amoxicillin Susceptibility}

Antibiotics kill the pathogenic bacteria in a way of their different mode of actions [33] and are accordingly classified in different groups. Twelve antibiotics belonging four modes of actions (Protein synthesis inhibitor, Folate synthesis inhibitor, DNA synthesis inhibitor, Cell wall synthesis inhibitor) were tested to evaluate their current status of susceptibility to Proteus isolates. Strong antimicrobial resistance was found in folate synthesis inhibitor, cotrimoxazole, and in cell wall synthesis inhibitor, cephalosporins (Table 2). Among the $\beta$-lactam antibiotics underlying the cell wall synthesis inhibitor, cephalosporin resistance were strong whereas amoxicillin susceptibility underlying the same group was pronounced in all tested isolates. Therefore, the result ruled out the possibility that isolates were $\beta$-lactamase producer. Currently our in vitro data make evidence that the antibiotics underlying the protein and DNA synthesis inhibitors are most effective drugs for the infection caused by Proteus. Although both ampicillin and amoxicillin are the broad spectrum semi-synthetic antibiotics of group penicillin, ampicillin was less effective than amoxicillin. The obtained result should connect with their chemical structures since chemically amoxicillin is more polar compound than ampicillin. The radical attached to $\beta$ lactam ring may contain a polar group that broadens the spectrum of activity by allowing more drugs to enter Gram negative bacterial cell wall via porins. The radical in amoxicillin has the formula $-\mathrm{CHNH}_{2}\left[\mathrm{C}_{6} \mathrm{H}_{4} \mathrm{OH}\right]$ whereas the radical in ampicillin has the formula $-\mathrm{CHNH}_{2}\left[\mathrm{C}_{6} \mathrm{H}_{5}\right]$ (Figure 8). The phenolic acid, $-\mathrm{C}_{6} \mathrm{H}_{4} \mathrm{OH}$, in amoxicillin is probably allowing more drugs to cell wall via porins and possibly playing a crucial role to inhibit cell wall synthesis in isolates. 
Table 2. In vitro antimicrobial sensitivity profile

\begin{tabular}{|c|c|c|c|c|c|c|c|c|c|c|c|c|}
\hline \multirow{4}{*}{$\begin{array}{l}\text { Isolate (Pr. } \\
\quad \text { sp) }\end{array}$} & \multicolumn{12}{|c|}{ Tested antibiotics } \\
\hline & \multicolumn{4}{|c|}{ Protein synthesis inhibitor } & \multirow{3}{*}{$\begin{array}{c}\begin{array}{c}\text { Folate synthesis } \\
\text { inhibitor }\end{array} \\
\text { Cot } \\
\end{array}$} & \multirow{3}{*}{$\begin{array}{c}\text { DNA synthesis } \\
\text { inhibitor } \\
\text { Cip }\end{array}$} & \multicolumn{6}{|c|}{ Cell wall synthesis inhibitor } \\
\hline & \multicolumn{2}{|c|}{$\begin{array}{l}\text { tRNA binding } \\
\text { inh. } \\
\end{array}$} & \multicolumn{2}{|c|}{$\begin{array}{c}\text { Mistranslation by } \\
\text { tRNA }\end{array}$} & & & \multicolumn{2}{|c|}{ Aminopenicillin } & \multicolumn{4}{|c|}{ Cephalosporins } \\
\hline & Tet & Dox & Kan & Stp & & & Amp & Amx & Cep & Cef & $\mathrm{Cft}$ & $\mathrm{Cfz}$ \\
\hline $11(P v)$ & + & - & + & + & - & - & + & + & - & - & - & - \\
\hline $66_{1}(P p)$ & + & + & + & + & - & + & - & + & - & - & - & - \\
\hline $66_{2}(P h)$ & + & + & + & + & I & + & - & + & - & - & - & - \\
\hline $66_{3}(P p)$ & + & + & + & + & - & + & I & + & - & - & - & - \\
\hline $66_{4}(P p)$ & + & + & + & + & - & + & - & + & - & - & - & - \\
\hline $66_{5}(P p)$ & I & + & I & + & I & + & I & + & + & - & - & - \\
\hline $66_{6}(P p)$ & + & + & + & + & - & + & + & + & - & - & - & - \\
\hline $66_{7}(P p)$ & + & + & + & + & - & + & - & + & - & - & - & - \\
\hline $66_{8}(P p)$ & + & + & + & + & - & + & I & + & - & - & - & - \\
\hline $91_{1}(\mathrm{Pm})$ & I & I & - & I & - & I & - & + & - & - & - & - \\
\hline $91_{2}(\mathrm{Pm})$ & - & + & I & + & - & + & I & + & - & + & - & - \\
\hline
\end{tabular}

Signs used indicate as (+): Susceptible, (-): Resistant, I: Intermediately resistant. Tet-Tetracycline, Dox-Doxycycline, Kan-Kanamycin, Stp-

Streptomycin, Cot-Cotrimoxazole, Cip-Ciprofloxacon, Amp-Ampicillin, Amx-Amoxicillin, Cep-Cephradine, Cef-Cefixime, Cft-Ceftriaxone, CfzCeftazidime.

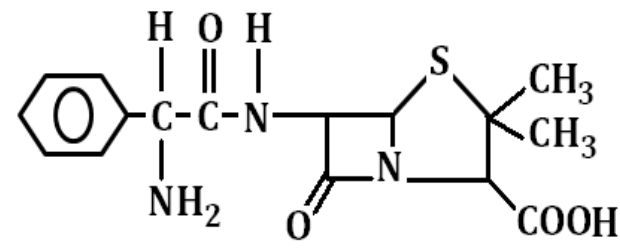

Ampicillin<smiles>CN(C(=O)C(N)c1ccc(O)cc1)C1C(=O)N2C1SC(C)(C)C2C(=O)O</smiles>

Amoxicillin

Figure 8. Chemical structure of two penicillins. Amoxicillin containing an additional hydroxyl group at 4-position of benzene ring exhibited more effectiveness than ampicillin

\section{Discussion}

Proteus are dimorphic bacteria, which in liquid media are motile, peritrichously flagellated short rods $(1-2 \mu \mathrm{m}$ in length with 6-10 flagella). These bacteria are called swimmer cells. However, when transferred onto solid media these short rods change into elongated (20-80 $\mu \mathrm{m}$ in length), hyperflagellated, multinucleated, nonseptated swarmer cells. The multinucleated cells migrate out from the inoculation site as long as the population of swarmer cells is reduced on solid surfaces [34]. The increased number of flagella is required for swarming movement of bacteria. Flagellin, a surfactant secreted by the flagellum acts as lubricant to facilitate this movement. Surfactant production is commonly regulated by quorum sensing [35]. In this study, the kinetic analysis of swarming motility revealed that the rate of swarming is decreasing with increasing incubation time. Recently O'Loughlin et al 2013 showed that the human pathogen Pseudomonas aeruginosa uses quorum sensing to control virulence and biofilm formation [36]. We, therefore, speculated that after a certain period of migration the isolates use quorum sensing to express new pathogenic factors like biofilm. We cannot rule out the possibility that the partial evaporation of water during longer incubation time may make the agar surface hard/rough enough to reduce the driving force of rotating flagella and thereby decreasing the rate of swarming with time.

Although bacteria of the genus Proteus can move by means of twitching motility, and this virulence factor plays an important role in biofilm formation in Pseudomonas [37], it has not previously been explored in detail in Proteus. This virulence factor was more expressed in CAUTI isolates [38], but none of the isolates moved over the whole plate [15]. In our study no Proteus isolates from tap water were able to twitch over the catheter bridge, it is probably due to their less pathogenic potentialities than CAUTI isolates. In biofilm forming abilities most of the isolates positively formed biofilm on PVC strip. Apparently biofilm quantification was directly proportional to the spectrum of resistance and swarming motility of isolates. The catheter bag from Protos brand showed better properties than that of Huaian brand regarding the prevention of biofilm formation of Proteus isolates. Here obtained results suggest that low cost catheter bags are relatively unsafe to prevent CAUTI in ascending route.

In Bangladesh, people are not aware about the schedule use of antibiotics. Therefore, the high incidence of multidrug resistant might be due to indiscriminate use of antibiotics, which may eventually supersede the drug resistant microorganisms from antibiotic saturated environment. We earlier reported the emergence of multidrug resistant, especially strong cephalosporin resistant Proteus strains in urban tap water and where only amoxicillin showed a satisfactory inhibition of all Proteus strains [21,22]. Now-a-days, the extensive use of cephalosporins in Bangladesh offered the pathogens to be resistant to them but the drugs of protein and DNA synthesis inhibitors (Table 2) were effective enough for the infection control and management. The amine group 
of amoxicillin provides increased polarity to expand its spectrum to include Gram negative bacteria. In addition, the phenolic acid present in amoxicillin is an ionizable group, which prevents zwitterions formation. It is also electron withdrawing, which together increases absorption and acid stability. Only streptomycin and amoxicillin were most effective antibiotics among tested others to inhibit the Proteus strains.

\section{Conclusion}

The rate of swarming growth of Proteus on LB-agar plate was decreasing with increasing incubation time. Urine drainage bag from Protos brand was relatively safer than that of Huaian brand to prevent CAUTI. Proteus isolates were strong resistant to cotrimoxazole and cephalosporins. Antibiotics underlying the protein and DNA synthesis inhibitors were satisfactorily effective and amoxicillin was the best of choice for the inhibition of Proteus isolates.

\section{Acknowledgements}

The authors wish to thank the Department of Pharmacy, University of Rajshahi, Bangladesh for providing laboratory facilities to carry out the entire experiments.

\section{Authors' Contribution}

AC designed and guided the study, and drafted the manuscript; AW worked out the experimental part.

\section{Funding}

No external funding was received for this research work.

\section{Conflict of Interest}

Authors' have no conflict of interest.

\section{References}

[1] Kunin, C.M., Care of the urinary catheter: Urinary tract infections, detection, prevention and management, $5^{\text {th }} \mathrm{Ed}$. Williams \& Wilkins, Baltimore, 1997, 227-279.

[2] Stamm, W.E., "Catheter-associated urinary tract infections: epidemiology, pathogenesis and prevention,” Am J Med, 91(3), 65S-71S, Sep 1991.

[3] Warren, J.W., "The catheter and urinary tract infection," Med Clin North Am, 75(2), 481-493, Mar 1991.

[4] Siebert, J.D., Thomson, R.B., Tan, J.S. and Gerson, L.W., "Emergence of antimicrobial resistance in gram-negative bacilli causing bacteremia during therapy,” Am J Clin Pathol, 100(1), 4751, May 1993.

[5] Jarlier, V., Fosse, T. and Philippon, A., “Antibiotic susceptibility in aerobic gram-negative bacilli isolated in intensive care units in 39 French teaching hospitals," Intensive Care Med, 22(10), 10571065, Oct 1996.

[6] Saint, S. and Chenoweth, C.E., "Biofilm and catheter-associated urinary tract infections," Infect Dis Clin North Am, 17(2), 411-32, Jun 2003.

[7] Maki, D.G. and Tambyah, P.A., "Engineering out the risk for infection with urinary catheters,” Emerg Infect Dis, 7(2), 342-347, Mar-Apr 2001.
[8] Saint, S., Lipsky, B.A. and Goold, S.D., "Indwelling urinary catheters: a one-point restraint,” Ann Intern Med, 137(2), 125-7, Jul 2002.

[9] Rozalski, A., Sidorczyk, Z. and Kotelko, K., "Potential virulence factors of Proteus bacilli,” Microbiol Mol Biol Rev, 61(1), 65-89, Mar 1997.

[10] Rashid, M.H. and Kornberg, A., "Inorganic polyphosphate is needed for swimming, swarming and twitching motilities of Pseudomonas aeruginosa,” PNAS, 97(9), 4885-4890, Apr 2000.

[11] Costerton, J.W., "Introduction to biofilm," Int J Antimicrob Agents, 11(3-4), 217-221, May 1999.

[12] Bagge, N., Ciofu, O., Skovgaard, N.T. and Hoiby, N., "Rapid development in vitro and in vivo of resistance to ceftazidime in biofilm-growing Pseudomonas aeruginosa due to chromosomal $\beta$ lactamase,” APMIS, 108(9), 589-600, Jul 2000.

[13] Chandra, J., Mukherjee, P.K., Leidich, S.D., Faddoul, F.F., Hoyer, L.L., Douglas, L.J. and Ghannoum, M.A., “Antifungal resistance of candidal biofilm formed on denture acrylic in vitro," J Dent Res, 80(3), 903-908, Mar 2001.

[14] Xu, K.D., McFeters, G.A. and Stewart, P.S., "Biofilm resistance to antimicrobial agents,” Microbiology, 146(3), 547-549, Mar 2000.

[15] Hola, V., Peroutkova, T. and Ruzicka, F., "Virulence factors in Proteus bacteria from biofilm communities of catheter-associated urinary tract infections,” FEMS Immunol Med Microbiol, 65(2), 343-349, Jul 2012.

[16] Dewanti, R. and Wong, A.C.L., "Influence of culture conditions on biofilm formation by Escherichia coli O157:H7,” Int J Food Microbiol, 26(2), 147-164, Jul 1995.

[17] Uhlich, G.A., Cooke, P.D. and Solomon, E.B., “Analyses of the red dry-rough phenotype of an Escherichia coli O157:H7 strain and its role in biofilm formation and resistance to antibacterial agents,” Appl Environ Microbiol, 72(6), 2564-2572, Apr 2006.

[18] Uhlich, G.A., Sinclair, J.R., Warren, N.G., Chmielecki, W.A. and Fratamico, P., "Characterization of Shiga toxin-producing Escherichia coli isolates associated with two multistate food-borne outbreaks that occurred in 2006," Appl Environ Microbiol, 74(4), 1268-1272, Feb 2008.

[19] Klayman, B.J., Volden, P.A., Stewart, P.S. and Camper, A.K., "Escherichia coli O157:H7 requires colonizing partner to adhere and persist in a capillary flow cell,” Environ Sci Technol, 43(6), 2105-2111, Feb 2009.

[20] Donlan, R.M., "Biofilm formation: A clinically relevant microbiological process,” Clin Infec Dis, 33(8), 1387-92, Oct 2001.

[21] Wadud, A. and Chouduri, A.U., "Microbial safety assessment of municipal water and incidence of multi-drug resistant Proteus isolates in Rajshahi, Bangladesh,” Curr Res Microbiol Biotechnol, 1(4), 189-195, Jul 2013.

[22] Chouduri, A.U. and Wadud, A., "Strong cephalosporin resistant uropathogen, Proteus mirabilis, in urban tap water harbors a risk to public health, Bangladesh,” Glo Adv Res J Microbiol, 2(10), 164171, Nov 2013.

[23] Chouduri, A.U., Wadud, A. and Islam, A.U., "Extended spectrum multi-drug resistance versus pathogenic factors- swarming, proteases, and urease- of Proteus species," Int Res J Microbiol, 4(10), 232-237, Dec 2013.

[24] Lopez-Lopez, G., Pascual, A. and Perea, J., "Effect of plastic catheter material on bacterial adherence and viability," J Med Microbiol, 34(6), 349-353, Jun 1991.

[25] O’Toole, G.A. and Kolter, R., "Initiation of biofilm formation in Pseudomonas fluorescens WCS365 proceeds via multiple, convergent signaling pathways: A genetic analysis,” $\mathrm{Mol}$ Microbiol, 28(3), 449-461, Apr 1998.

[26] Aiassa, V., Barnes, A.I. and Albesa, I., "Macromolecular oxidation in planktonic population and biofilm of Proteus mirabilis exposed to ciprofloxacin,” Cell Biochem Biophys, 1-6, Jun 2013.

[27] Deighton, M.A., Capstick, J., Domalewski, E. and Van, N.T., "Methods for studying biofilm produced by Staphylococcus epidermidis," Methods in Enzymol, 336, 177-195, 2001.

[28] Matsuyama, T., Takagi, Y., Nakagawa, Y., Itoh, H., Wakita, J. and Matsushita, M., "Dynamic aspects of the structured cell population in a swarming colony of Proteus mirabilis, " J Bacteriol, 182(2), 385-393, Jan 2000.

[29] Mulhall, A.B., Chapman, R.G. and Crowe, R.A., "Bacteriuria during indwelling urethral catheterization,” J Hospital Infec, 11(3), 253-262, Apr 1988. 
[30] Sabbuba, N., Hughes, G. and Stickler, D.J., "The migration of Proteus mirabilis and other urinary tract pathogens over Foley catheters,” BJU Int, 89(1), 55-60, Jan 2002.

[31] Jones, B.V., Young, R., Mahenthiralingam, E. and Stickler, D.J., "Ultrastructure of Proteus mirabilis swarmer cell rafts and role of swarming in catheter-associated urinary tract infections," Infect Immun, 72(7), 3941-3950, Jul 2004.

[32] Liedl, B., "Catheter-associated urinary tract infections," Curr Opin Urol, 11(1), 75-79, Jan 2001.

[33] Peach, K.C., Bray, W.M., Winslow, D., Liningtond, P.F. and Linington, R.G., "Mechanism of action-based classification of antibiotics using high-content bacterial image analysis," Mol Bio Syst, 9, 1837-1848, Apr 2013.

[34] Rozalski, A., Sidorczyk, Z. and Kotelko, K., "Potential virulence factors of Proteus bacilli,” Microbiol Mol Biol Rev, 61(1), 65-89, Mar 1997.
[35] Lindum, P.W., Anthoni, U., Christophersen, C., Eberl, L., Molin, S. and Givskov, M., "N-acyl-L-homoserine lactone autoinducers control production of an extracellular lipopeptide biosurfactant required for swarming motility in Serratia liquefaciens MG1," $J$ Bacteriol, 180(23), 6384-6388, Dec 1998.

[36] O’Loughlin, C.T., Miller, L.C., Siryaporn, A., Drescher, K., Semmelhack, M.F. and Bassler, B.L., "A quorum-sensing inhibitor blocks Pseudomonas aeruginosa virulence and biofilm formation," PNAS, 110(44), 17981-17986, Oct 2013.

[37] Mattick, J.S., “Type IV pili and twitching motility,” Annu Rev Microbiol, 56, 289-314, Oct 2002.

[38] Stickler, D. and Hughes, G., "Ability of Proteus mirabilis to swarm over urethral catheters,” Eur J Clin Microbiol Infect Dis, 18(3), 206-208, Apr 1999. 